\title{
The effect of practice on binocular rivalry control
}

\author{
LEON C. LACK 1 \\ UNIVERSITY OF ADELAIDE
}

The effects of passive viewing and the practice of the control instructions, "slow rate" and "rapid rate," on a measure of binocular rivalry (BR) control was investigated. Four groups of 8 Ss each had different amounts of passive viewing of BR followed by different amounts of control instructions to complete a total of 50 min of testing spaced over 10 days. There were increases of passive rate as long as Ss practiced only the "passive rate" instructions. This had an effect of increasing the rapid rate and slow rate of the first control practice day. However, "passive rate" practice had no significant effect on the measure of $B R$ control. Successive practice days of "rapid rate" and "slow rate" instructions produced an increase in rapid rate and decrease in slow rate resulting in an increase in the measure of control.

When the two eyes are independently and continuously stimulated with dissimilar monocular patterns the $S$ perceives an alternation between the patterns that is known as binocular rivalry. It has been recognized for a considerable time that binocular rivalry can be affected by voluntary control (Helmholtz, 1925; Breese, 1901; McDougall, 1903; Washburn \& Gillette, 1933; George, 1936).

The extent of voluntary control may be measured by instructing the $S$ to decrease or increase the rate of alternation for a given test period. A comparison of the rate under the "decrease" instructions with the rate under the "increase" instructions provides a measure of control. Meredith and Meredith (1962) found a highly significant effect of their instructional conditions of "rapid rate" and "slow rate" on the rate of binocular rivalry. The mean "slow rate" and "rapid rate" for their $24 \mathrm{Ss}$ were 18.06 reversals per minute and 50.96 reversals per minute, respectively.

Investigators have usually found an increase of BR rate with spaced practice but not during massed practice of passive viewing (Aafjes, Hueting, \& Visser, 1966). Cogan and Goldstein (1967) suggest that "rest periods" during spaced practice provide a motivating factor for Ss to follow unintentionally inferred instructions to increase the $B R$ rate. This would suggest that during spaced "passive rate" viewing Ss may, to some extent, be practicing some internally derived type of "rapid rate" instructions.

It is also not clear from the literature what the effects are of passive viewing on BR control. It could be that "passive rate" viewing increases the familiarity of the $S$ to both phases of the rivalry stimulus thereby increasing the $S$ 's ability to control the rate. On the other hand "passive" viewing may increase both the first rapid rate and slow rate when tested and therefore not affect BR control.

Because of the lack of information on the effects of spaced practice of "passive rate" and the control instructions "rapid rate" and "slow rate" on the extent of control of binocular rivalry, the purpose of this experiment is to investigate the extent to which the control of binocular rivalry is altered by spaced practice of these instructional conditions.

\section{Subjects}

\section{METHOD}

Sixteen males and 16 females were selected randomly from an introductory psychology class to serve as Ss. All Ss had normal or corrected to normal vision and were naive with respect to the rivalry situation and to the purpose of the experiment.

\section{Stimulus}

The rivalry stimulus consisted of left and right black fusion circles $58 \mathrm{~mm}$ apart, each subtending $9.5 \mathrm{deg}$ at the retina. The black fusion circles were centered on square white fields, each subtending $28 \mathrm{deg}$ at the retina. The white field was on a black ground providing a second fusion contour for the two fields. A black vertical line of $1 \mathrm{deg}$ in width bisected the right fusion circle and a black horizontal line $1 \mathrm{deg}$ in width bisected the left fusion circle. The intensities of the two white fields were equal and kept constant throughout the experiment.

\section{Apparatus and Procedure}

The apparatus consisted mainly of a Stereo King Model HN-44 stereoscope in which could be mounted a $4 \times 10 \mathrm{~cm}$ stereocard $5.5 \mathrm{~cm}$ from refracting lenses. This provided fixation at infinity for normal vision. The fusion circles and rivalry lines were inked on thin white paper and mounted in the black stereocard. Each stimulus was transilluminated by a $75-\mathrm{W}, 240-\mathrm{V}$ incandescent bulb placed $80 \mathrm{~cm}$ behind the stereocard. The luminance of the black fusion circles, vertical and horizontal line as measured at the lens by an S.E.I. spot photometer, was $.62 \mathrm{ft}-\mathrm{L}$. The background luminance was a uniform $4.5 \mathrm{ft}-\mathrm{L}$. A chin rest was adjusted for the $S$ who sat in a sound deadened and dimly lit room and received instructions through headphones from $E$ in an adjacent room. The $S$ tapped a telegraph key with his preferred hand to indicate a dominance change in binocular rivalry during timed trials. A tap of the key activated a digital counter in E's room allowing the rivalry rate to be recorded for a timed trial. There were 10 timed trials in each of 10 consecutive test days. Each trial was $30 \mathrm{sec}$ in duration with $30 \mathrm{sec}$ of rest between trials. The Ss were given the general instructions to look into the stereoscope and fixate at the apparent intersection point of the two lines at the "ready" signal, to tap the telegraph key once for each dominance change in rivalry after the "start" signal, and to stop tapping and to look away at the "stop" signal. Although Cogan and Goldstein (1967) noted that there are periods when both patterns seem to be present, the contours of one line will predominate over the other at the expected intersection point. Since a dichotomous classification is possible at all times, it is not unreasonable to instruct $S s$ to indicate dominance changes. Cogan and Goldstein (1967) also found "no meaningful relationship between blink rate and rivalry rate." Nevertheless, all Ss were instructed not to blink excessively, and occasional checks by direct observation of a second $E$ were made on Ss' blink rates.

In addition, the Ss received one of three different instructions for any one test trial. The instructions were similar to those used by Meredith and Meredith (1962) of "natural rate," "slow rate," and "rapid rate." The equivalent of their "natural rate," was the "passive rate" instruction. Passive rate: "You are to look at the pattern in a passive manner. Look at the intersection point of the vertical and horizontal bar. At any instant one of the bars will be dominant in that it is solid or continuous while the other is broken or fades out at the intersection point. This bar will not remain dominant for the dominance will change to the other bar. Do not assist or hold back this change of dominance. Do not try 
Table 1

Experimental Design. S - "Slow Rate" Instruction. R - "Rapid Rate" Instruction.

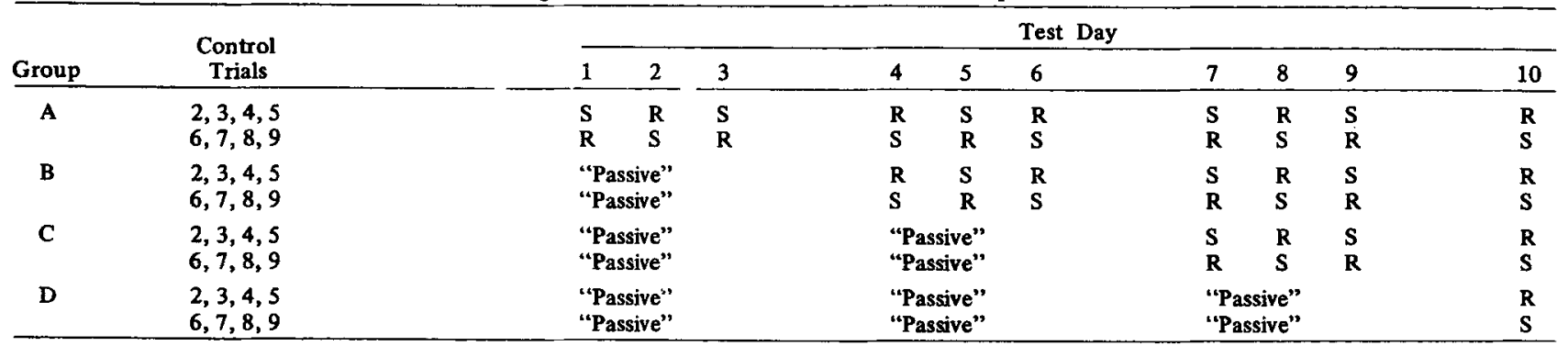

to control the rate of alternation. Just relax and with an aloof passive attitude let the bars alternate at their own natural rate." Slow rate: "You are to exert control over the rivalry rate by making the dominance of the patterns change as slowly as possible. Look at the intersection point of the vertical and horizontal bars. At any instant one of the bars will be dominant in that it is solid or continuous while the other bar is broken or fades out at the intersection point. Always concentrate on the dominant bar to hold it dominant as long as possible or suppress the nondominant bar to keep it from becoming dominant. If, eventually, the dominance changes, apply the same procedure to maintain the new dominant bar as long as possible. In this way slow down the rate of "alternations." Rapid rate: "You are to exert control over the rivalry rate by making the dominance of the patterns change as rapidly as possible. Look at the intersection point of the vertical and horizontal bars. At any instance one of the bars will be dominant in that it is solid or continuous while the other bar is broken or fades out at the intersection point. To make the changes take place rapidly concentrate on or attend to the bar that is not dominant to bring it into dominance, or suppress the dominant bar to make it nondominant. When a change in dominance takes place, apply the same procedure to make the alternations take place as rapidly as possible."

The 32 Ss were divided randomly into 4 groups, each containing 4 males and 4 females. The 4 groups had different amounts of passive viewing and control practice (see Table 1). Group A had "slow rate" and "rapid rate" instruction on all 10 test days. Group B had 7 test days of control instruction starting on Test Day 4. Group $C$ had 4 test days of control instruction starting on Test Day 7. Group D had "slow rate" and "rapid rate" instructions only on Test Day 10 . Until the first control practice day for Groups B, C, and D, all 10 trials on each day were "passive rate" instructions. On all control practice days, the first and 10th trial remained "passive rate" instructions and the middle eight trials received the control instructions. The "slow rate" instructions were first (Trials $2,3,4,5$ ) followed by "rapid rate" instructions (Trials $6,7,8,9$ ) on odd-numbered test days, alternating with "rapid rate" followed by "slow rate" on even numbered test days. All Ss remained naive to the "slow rate" and "rapid rate" instructions until their first control practice day.

\section{RESULTS AND DISCUSSION}

When questioned on the first test day and on subsequent test days, all Ss reported no difficulty in indicating dominance changes. Periodic checks on blink rate confirmed that Ss were following instructions not to blink excessively. There were no significant differences in blink rates for any $\mathrm{Ss}$ between any of the conditions nor any change of blink rate over time. The measure of rivalry rate under the "slow rate" and "rapid rate" instructions was the same as that of Meredith and Meredith (1962), the number of dominance changes per minute. A percentage measure of control of binocular rivalry was devised incorporating a comparison of the rivalry rates under the "slow rate" and "rapid rate" instructions. Percentage control equals (100)(Rapid - Slow)/(Rapid + Slow).

This control measure applied to the slow and rapid rates of all Ss on the first control test day of each group yielded a mean percentage control for Group A-Day 1 of 42.6 , for Group BDay 4 of 46.3, for Group C-Day 7 of 39.1, and for Group D-Day 10 of 53.2. The overall mean percentage control for all Ss on their first control practice day was 45.3. This same control measure applied to the Mean Rapid Rate and Slow Rate of Meredith and Meredith's (1962) Ss produced a very similar mean percentage control of 47.7 .

Figure 1 shows graphically the rivalry rate for each of the groups under the "slow rate" instructions. The effect of passive viewing on the slow rate can be tested by comparing means of the first "slow rate" practice day of all groups. A simple analysis of variance applied to Group A-Day 1, Group B-Day 4, Group CDay 7, and Group D-Day 10 found a significant effect $(F=3.09$, $\mathrm{df}=3 / 31, \mathrm{p}<.05$ ) of passive viewing on slow rate. A trend analysis using "orthogonal polynomials" (McNemar, 1962) showed that the significant difference between groups was produced by a significant linear increase $(F=8.84, \mathrm{df}=1 / 31$,

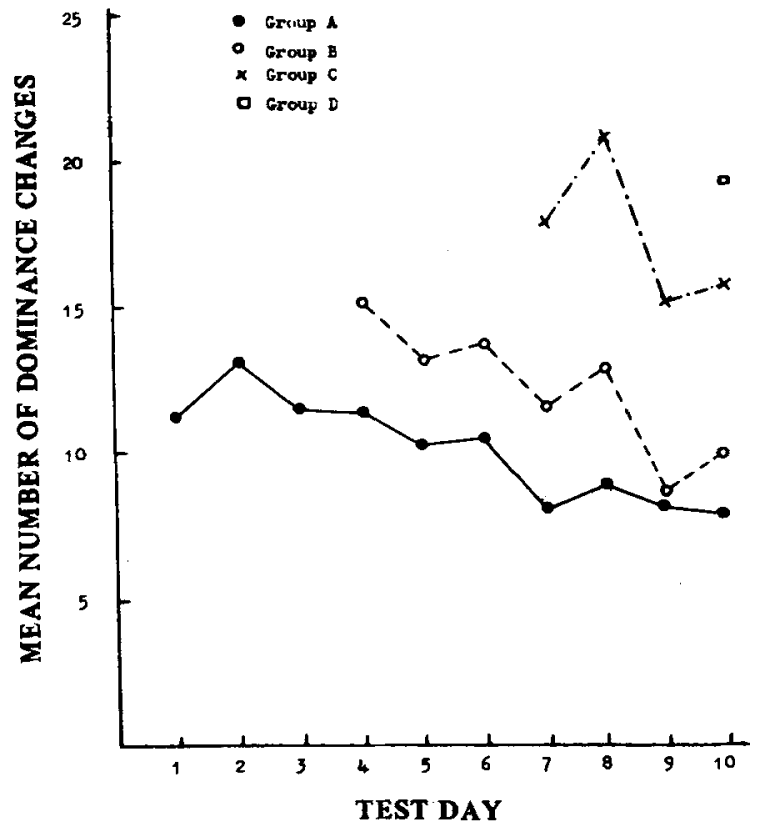

Fig. 1. Mean rivalry rate per min under "slow rate" instruction. 


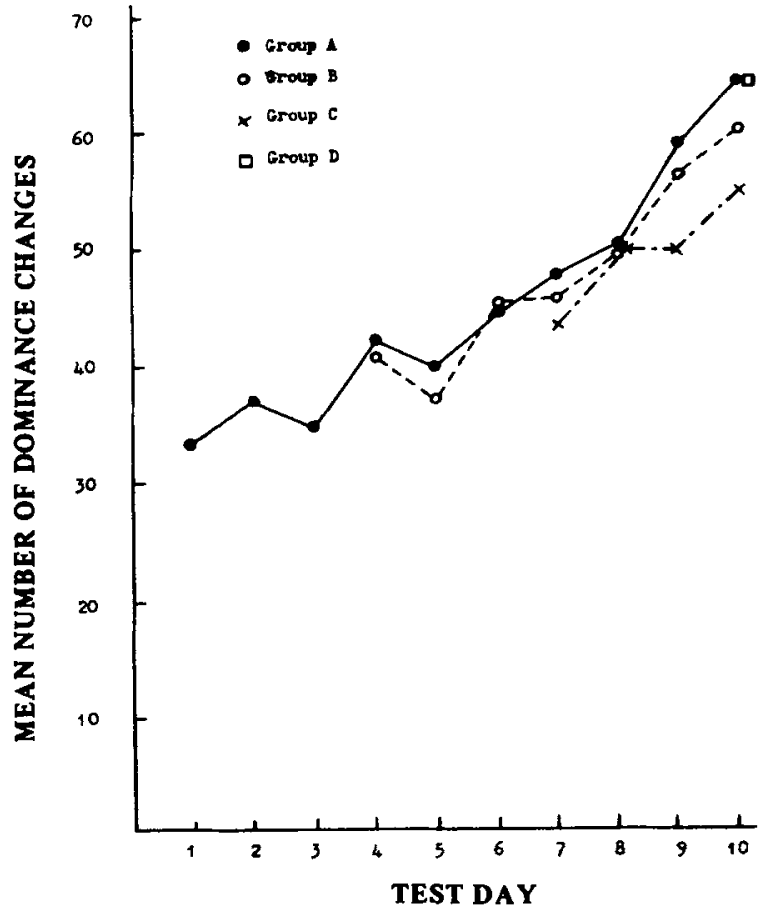

Fig. 2. Mean rivalry rate per min under "rapid rate" instruction.

$p<.02)$. The cumulative effect of "slow rate" instructions on slow rate can be tested by applying a treatments by subject design analysis of variance (Lindquist, 1953) to each group across the practice days of "slow rate." Group A showed a significant difference across Test Days 1 through $10(\mathrm{~F}=3.79$, $\mathrm{df}=9 / 63$, $\mathrm{p}<.001)$. Group B showed a significant difference across Test Days 4 through $10(F=4.44, d f=6 / 55, p<.005)$. Group $C$ showed a significant difference across Test Days 7 through 10 $(\mathrm{F}=6.96, \mathrm{df}=3 / 31, \mathrm{p}<.005)$. In summary, the effect of "passive rate" instruction alone was to increase the rivalry rate under the first "slow rate" instructions, whereas the effect of subsequent "slow rate" instructions on every group was a decrease of slow rivalry rate over practice days. Since these two instructions have opposite effects on the slow rate, it is not surprising to find a significant difference of slow rate between groups on Test Day $10(\mathrm{~F}=8.43, \mathrm{df}=3 / 31, \mathrm{p}<.001)$.

Figure 2 shows graphically the rivalry rates under "rapid rate" instructions for each group. The effect of passive viewing on the first "rapid" rivalry rate, can be tested by comparing means of the first "rapid rate" practice day of all groups. A simple analysis of variance applied to Group A-Day 1, Group B-Day 4, Group C-Day 7, and Group D-Day 10 found a significant effect $(F=4.64, \mathrm{df}=3 / 31, \mathrm{p}<.01)$ of passive viewing on rapid rate. The first "rapid rate" seems to be a linearly increasing function $(F=12.02, \mathrm{df}=3 / 31, \mathrm{p}<.01)$ of the number of days of "passive rate" only. The cumulative effect of "rapid rate" instructions on rapid rate can be tested by applying a treatments by subject analysis of variance to each group over the practice trials of "rapid rate." Group A showed a difference across Test Days 1 through $10(F=8.22$, df $=9 / 63, p<.001)$. Group B showed a significant difference across Test Days 4 through $10(F=7.04$, $\mathrm{df}=6 / 55, \mathrm{p}<.001$ ). Group $\mathrm{C}$ showed a significant difference across Test Days 7 through $10(F=5.60, \mathrm{df}=3 / 31, \mathrm{p}<.01)$. Therefore, th.e effect of both "passive rate" and "rapid rate" instructions are to increase the rivalry rate under "rapid rate" instructions. By testing the difference between groups on Test Day 10, any difference in the magnitude of effect of the two instructions on rapid rate can be compared. If "rapid rate" has more effect than "passive rate" instructions on increasing the rapid rate, there should be a linear increase in rapid rate on Day 10 from Group D to Group A. Group A would show the greatest rapid rate if "rapid rate" instructions were more effective than "passive rate" instructions at increasing the rapid rate. However, there is no significant difference between groups $(F=0.22)$, nor is there any linear trend $(F=1.0)$. Therefore, there is no significant difference between the effects of "passive rate" and "rapid rate" instructions on the increase of rivalry rate over test days as tested under "rapid rate" instructions.

The reason for the increased slow and rapid rates of Groups C and $D$ with prior passive viewing becomes evident when the passive rivalry rates are analyzed in these two groups. A treatment by subjects analysis of variance applied to Group $C$-Days 1 through 6 shows a significant linear increase $(F=8.15, \mathrm{df}=1 / 35$, $p<.001)$ of passive rivalry rate. The same analysis applied to Group D-Days 1 through 9 also shows a significant linear increase of passive rivalry rate $(F=18.7$, df $=1 / 56, p<.001)$. Using a Spearman Rank Correlation Test it was found that those Ss who showed the highest passive rate in Group $C$ on Day 6 had the highest slow rate $\left(r_{s}=+.93, n=8, p<.02\right)$ and highest initial rapid rate $\left(r_{s}=+.90, n=8, p<.02\right)$ on Day 7 . Those $S s$ in Group D who showed the highest passive rate on Day 9 had the highest rapid rate $\left(I_{s}=+.91, n=8, p<.02\right)$ and tended to have a higher slow rate $\left(r_{s}=+.54, n=8, p<.10\right)$ on Day 10. In summary, the increased slow and rapid rates of Groups $C$ and D on their first control practice days are due to the general increase of passive rates during days of only "passive rate" instructions.

Figure 3 shows graphically the measure of binocular rivalry control (100)(Rapid - Slow)/(Rapid + Slow) for each group on

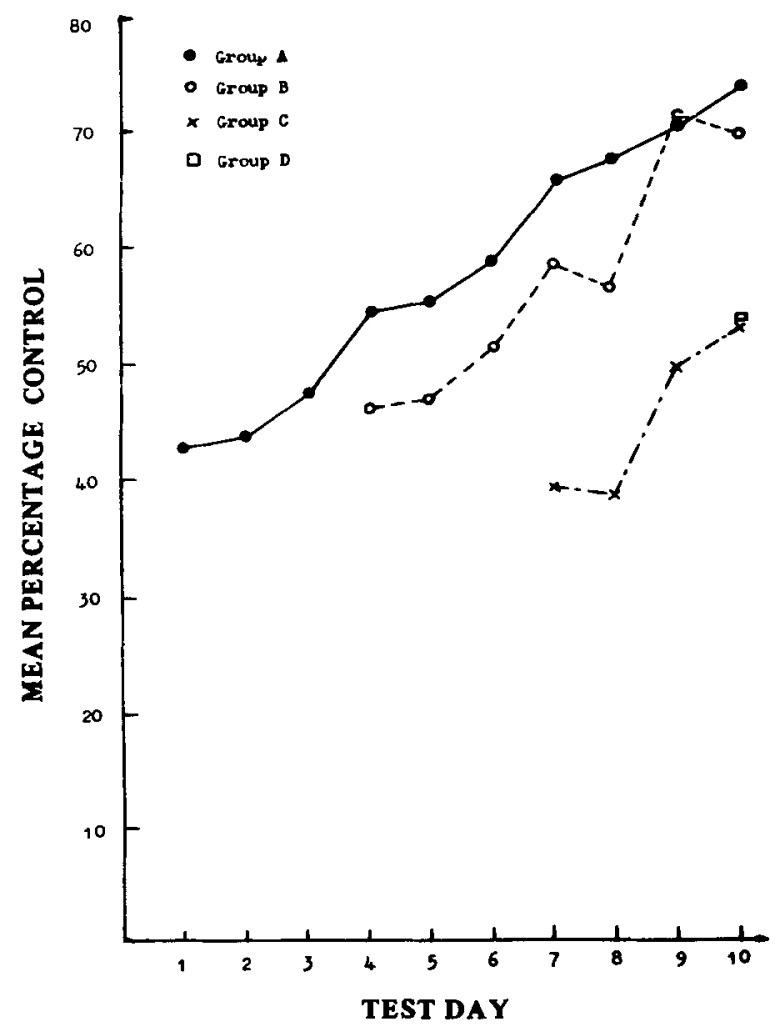

Fig. 3. Mean percentage control under "slow rate" and "rapid rate" instructions. 
Table 2

Effect of Further Practice of "Slow Rate" and "Rapid Rate" Instruction on the BR Control of Two Subjects from Group A

\begin{tabular}{lccccccc}
\hline & \multicolumn{3}{c}{ Subject R. G. } & & \multicolumn{3}{c}{ Subject C. T. } \\
\cline { 7 - 8 } \cline { 6 - 7 } Dayt & "Slow" & "Rapid" & Control & & "Slow" & "Rapid" & Control \\
\hline 10 & 7 & 134 & 90.1 & & 10 & 62 & 72.3 \\
11 & 8 & 156 & 90.3 & 8 & 67 & 78.6 \\
12 & 8 & 201 & 92.3 & & 9 & 63 & 75.0 \\
13 & 4 & 199 & 96.1 & & 7 & 66 & 80.8 \\
14 & 4 & 200 & 96.1 & & 7 & 68 & 81.4 \\
15 & 3 & 231 & 97.5 & 6 & 71 & 84.4 \\
16 & 5 & 207 & 95.3 & & 5 & 73 & 87.2 \\
17 & 4 & 245 & 96.8 & & 3 & 76 & 92.4 \\
18 & 2 & 242 & 98.4 & & 2 & 83 & 95.3 \\
19 & 2 & 259 & 98.5 & & 2 & 87 & 95.5 \\
20 & 1 & 278 & 99.3 & 1 & 89 & 97.8 \\
\hline
\end{tabular}

test days for which "rapid rate" and "slow rate" instructions were given. The effect of passive viewing on control can be tested by comparing the four groups' control values on the first day of "slow rate" and "rapid rate" instructions. A simple analysis of variance was applied to Group A-Day 1, Group B-Day 4, Group C-Day 7, and Group D-Day 10 . There was no significant difference between groups on their first day of control practice $(F=1.32$, df $=3 / 31, p>.25)$. To test the effect of practicing the "slow rate" and "rapid rate" instructions on the control of binocular rivalry a treatment by subject analysis of variance was applied across the practice days of each group. Group A showed a significant difference in control across Test Days 1 through 10 $(F=7.85, \mathrm{df}=9 / 63, \mathrm{p}<.001)$. Group $\mathrm{B}$ showed a significant difference across Test Days 4 through $10(\mathrm{~F}=12.7$, $\mathrm{df}=6 / 55$, $\mathrm{p}<.001)$. Group $\mathrm{C}$ showed a significant difference across Test Days 7 through $10(F=8.12$, df $=3 / 31, p<.001)$. Since control does not significantly change with passive viewing but does increase over successive days of practice of the "slow rate" and "rapid rate" instructions, it is not surprising to find a significant difference in control between groups on Test Day $10(F=4.61$, df $=3 / 31, p<.01$ ).

To get some idea of the extent to which control could be increased with further practice, two volunteers from Group A (R.G. above average initial control and C.T. below average initial control) were given "slow rate" and "rapid rate" instructions for another 10 test days. The rivalry rates for both instructions in reversals per minute and control percentages are given in Table 2 . Both R.G. and C.T. show continued decrease of slow rate and increase of rapid rate over Test Days 10 through 20. As a result, their percentage control measures asymptotically approach 100 . By Day 20 both Ss show a remarkable ability to hold one pattern dominant over the other in the slow rate as indicated by a rivalry rate of only one alternation per minute.

In summary, the more passive viewing a $S$ has before the instructions of "slow rate" and "rapid rate," the greater will be his rivalry rates under both of these control instructions. However, passive viewing does not affect significantly the extent of binocular rivalry control. Control increases very significantly with spaced practice of both control instructions and approaches asymptotic performance with continued practice.

\section{REFERENCES}

AAFJES, M., HUETING, J. E., \& VISSER, P. Individual and interindividual differences in binocular retinal rivalry in man. Psychophysiology, 1966, 3, 18-22.

BREESE, B. B. On inhibition. Psychological Monographs, 1901, 3, 1-65.

COGAN, R., \& GOLDSTEIN, A. G. The stability of binocular rivalry during spaced and massed viewing. Perception \& Psychophysics, 1967, 2, 171-174.

GEORGE, R. W. The significance of the fluctuation experienced in observing ambiguous figures and in binocular rivalry. Journal of General Psychology, 1936, 15, 39-66.

HELMHOLTZ, H. Von. Treatise on physiological optics. Vol. III. J. P. Southall (Ed.) New York: Dover, 1925.

LINDQUIST, E. F. Design and analysis of experiments in psychology and education. Boston: Houghton Mifflin, 1953.

McDOUGALL, W. Physiological factors of the attention process (III). Mind, 1903, 12, 473-488.

McNEMAR, Q. Psychological statistics. (3rd ed.) New York: Wiley, 1962.

MEREDITH, G. M., \& MEREDITH, C. G. W. Effect of instructional conditions on rate of binocular rivalry. Perceptual \& Motor Skills, 1962, $15,655-664$.

WASHBURN, M. F., \& GILLETTE, A. Studies from the Psychological Laboratory of Vassar College: LXII. Motor factors in voluntary control of cube perspective fluctuations and retinal rivalry fluctuations. American Journal of Psychology, 1933, 315-319.

\section{NOTE}

1. Address: Department of Psychology, University of Adelaide, Adelaide, South Australia.

(Accepted for publication April 7, 1969.) 